\title{
Glucocerebrosidase Mutations in Gaucher Disease
}

\author{
Ernest Beutler, Anna Demina, and Terri Gelbart \\ The Scripps Research Institute, La Jolla, California, U.S.A.
}

\begin{abstract}
Background: Thirty-six mutations that cause Gaucher disease, the most common glycolipid storage disorder, are known. Although both alleles of most patients with the disease contain one of these mutations, in a few patients one or both disease-producing alleles have remained unidentified. Identification of mutations in these patients is useful for genetic counseling.

Materials and Methods: The DNA from 23 Gaucher disease patients in whom at least one glucocerebrosidase allele did not contain any of the 36 previously described mutations has been examined by single strand conformation polymorphism (SSCP) analysis, followed by sequencing of regions in which abnormalities were detected.

Results: Eight previously undescribed mutations were detected. In exon 3, a deletion of a cytosine at cDNA nt 203 was found. In exon 6, three missense mutations were identified: a $\mathrm{C} \rightarrow \mathrm{A}$ transversion at $\mathrm{cDNA}$ nt 644
\end{abstract}

$\left(\mathrm{Ala}^{176} \rightarrow \mathrm{Asp}\right)$, a $\mathrm{C} \rightarrow \mathrm{A}$ transversion at $\mathrm{cDNA} \mathrm{nt}$ 66l that resulted in a (Pro ${ }^{182} \rightarrow$ Thr), and a G $\rightarrow$ A transition at cDNA nt $721\left(\mathrm{Gly}^{202} \rightarrow \mathrm{Arg}\right)$. Two missense mutations were found in exon $7: a \mathrm{G} \rightarrow \mathrm{A}$ transition at $\mathrm{CDNA}$ nt $887\left(\operatorname{Arg}^{257} \rightarrow \mathrm{Gln}\right)$ and a $\mathrm{C} \rightarrow \mathrm{T}$ at cDNA nt 970 $\left(\operatorname{Arg}^{285} \rightarrow\right.$ Cys). Two missense mutations were found in exon 9: a T $\rightarrow$ G at cDNA nt $1249\left(\operatorname{Trp}^{378} \rightarrow\right.$ Gly) and a $\mathrm{G} \rightarrow \mathrm{A}$ at cDNA nt 1255 ( $\mathrm{Asp}^{380} \rightarrow \mathrm{Asn}$ ). In addition to these disease-producing mutations, a silent $C \rightarrow G$ transversion at cDNA nt 1431, occurring in a gene that already contained the $1226 \mathrm{G}$ mutation, was found in one family.

Conclusions: The mutations described here and previously known can be classified as mild, severe, or lethal, on the basis of their effect on enzyme production and on clinical phenotype, and as polymorphic or sporadic, on the basis of the haplotype in which they are found. Rare mutations such as the new ones described here are sporadic in nature.

\section{INTRODUCTION}

Glucocerebrosidase is a lysosomal $\beta$-glucosidase that hydrolyzes glucosylceramide (glucocerebroside). Deficiency of the enzyme leads to accumulation of insoluble glucocerebrosides in the tissues, resulting in the clinical manifestations of Gaucher disease (1). Gaucher disease is a heterogeneous disorder even within its three subtypes. The majority of patients, those without neurologic manifestations of the disease, are classified as type I. Types II and III are neuronopathic forms, classified with respect to severity and to the time of onset of neurologic disease, type II being the most severe, with symptoms at or near the time of birth, and type III with later onset.

Over 30 point mutations, deletions, and gene

Address correspondence and reprint requests to: Ernest Beutler, The Scripps Research Institute, 10666 North Torrey Pines Road, La Jolla, CA 92037, U.S.A.

fusions and conversions with the homologous pseudogene have been previously reported in the gene coding for glucocerebrosidase (GBA) (2). These mutations and the new ones described here are summarized in Table 1 and in Fig. 1 . In patients of Jewish ancestry we have found that $97 \%$ of the mutations can be attributed to five of these mutations in the following order of frequency: $1226 \mathrm{G}, 84 \mathrm{GG}$, Ivs2(+1), 1448C, and $1297 \mathrm{~T}$ (3). In non-Jewish patients these five mutations account for $75 \%$ of the disease-producing alleles (4).

When both mutations causing this autosomal recessive disease are not identified, further investigation may be warranted to identify the responsible nucleotide change. This information may be useful in screening other family members for carrier status of the mutations as well as prenatal counseling. Genotype/phenotype correlations are important, since association of a mu- 


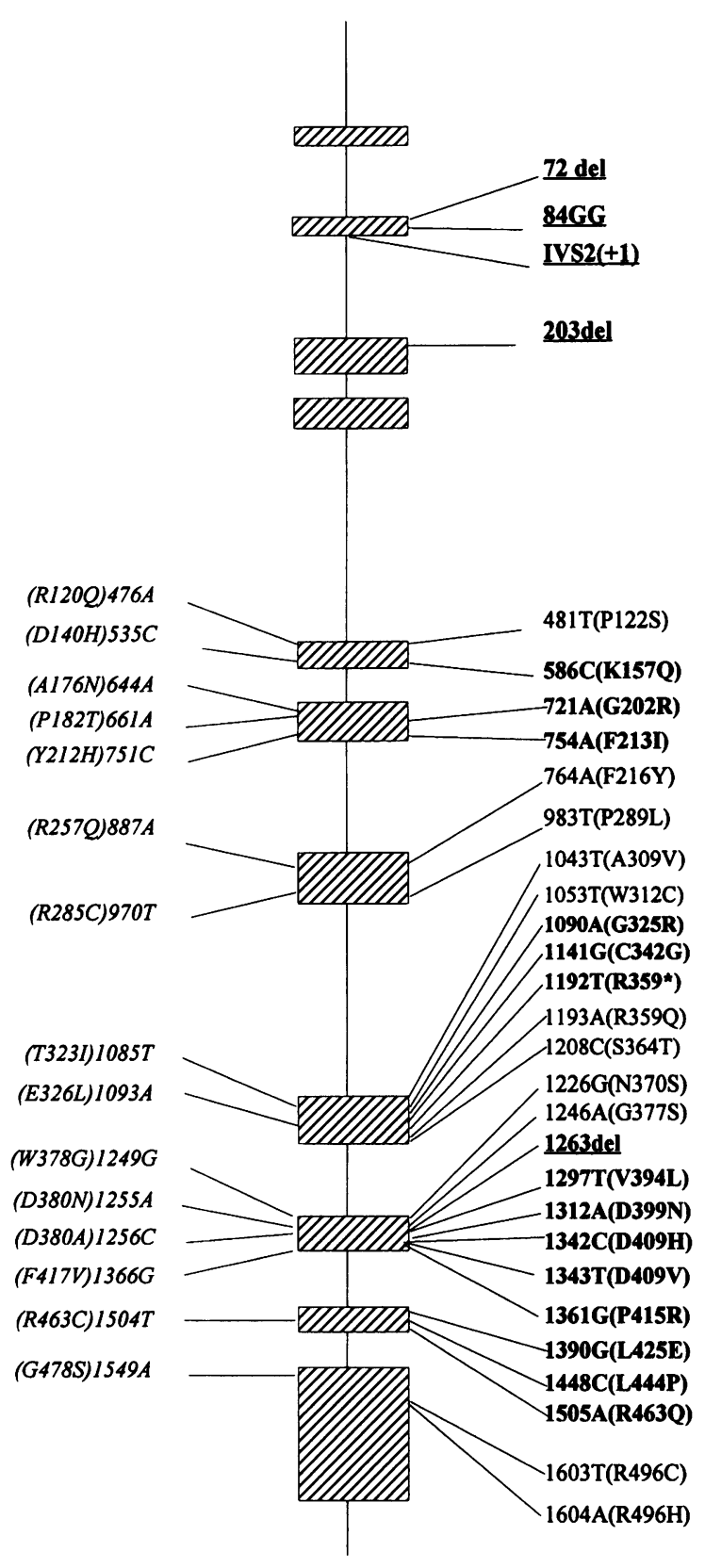

FIG. 1. The mutations of the glucocerebrosidase gene

At the right the deduced severity of each mutation is designated by the use of different type styles: lethal $=$ underline; severe $=$ bold; mild $=$ normal. At the left, mutations of unknown severity are shown in italics. The cDNA number followed by the base that is found at that position in the mutant are shown next to the line. Within parentheses the amino acid change is shown, where applicable. cDNA numbers are assigned with the upstream ATG beginning with 1 . Amino acid numbers are numbered beginning with the putative cleavage site of the leader sequence. tation with neurologic disease may have important implications in genetic counseling.

\section{MATERIALS AND METHODS}

DNA from leukocytes of 215 unrelated Gaucher disease patients (130 Jewish and 85 non-Jewish) was studied. Each sample was examined by the methods indicated in Table 1 for as many of the 36 mutations shown until the mutations on both alleles had been identified (Table 2). Four hundred and four of the 430 putative mutations were identified as indicated in previous publications from this laboratory (3-6).

DNA from 23 individuals (22 non-Jewish and 1 Jewish) with 26 unidentified alleles was subjected to single-stranded conformation polymorphism analysis (SSCP) as reported previously (5). With the following exceptions, all exons of all samples were examined, and in addition genomic nt 201-396 (7) containing the putative promotor was examined in all samples. The amount of DNA available was insufficient for us to be able to examine two exons in Patient 6,1 exon in Patient 4, and 1 exon in each of four other patients, each with a single remaining unidentified allele.

When abnormal bands were encountered in SSCP analysis, the DNA from that region of the glucocerebrosidase gene was amplified by the polymerase chain reaction (PCR) and sequenced (6) to determine the exact site of the mutation. To confirm the mutation, the opposite strand was also sequenced. In addition, if the mutation created or destroyed a restriction endonuclease site, this was used to further confirm the mutation. In some cases allele-specific oligonucleotide hybridization (ASOH) was used to confirm the mutations (Table 3).

Whenever a new mutation was found, all of the samples with unidentified Gaucher disease mutations were screened for the new mutation using either restriction endonuclease analysis or ASOH as indicated in Table 3.

\section{RESULTS}

When SSCP was carried out on exons 1 through 11 and the promotor region of the glucocerebrosidase gene, eight new mutations were detected in the 26 alleles with unidentified mutations that were examined (Table 4). The 644A mutation was found in one additional unrelated patient, 


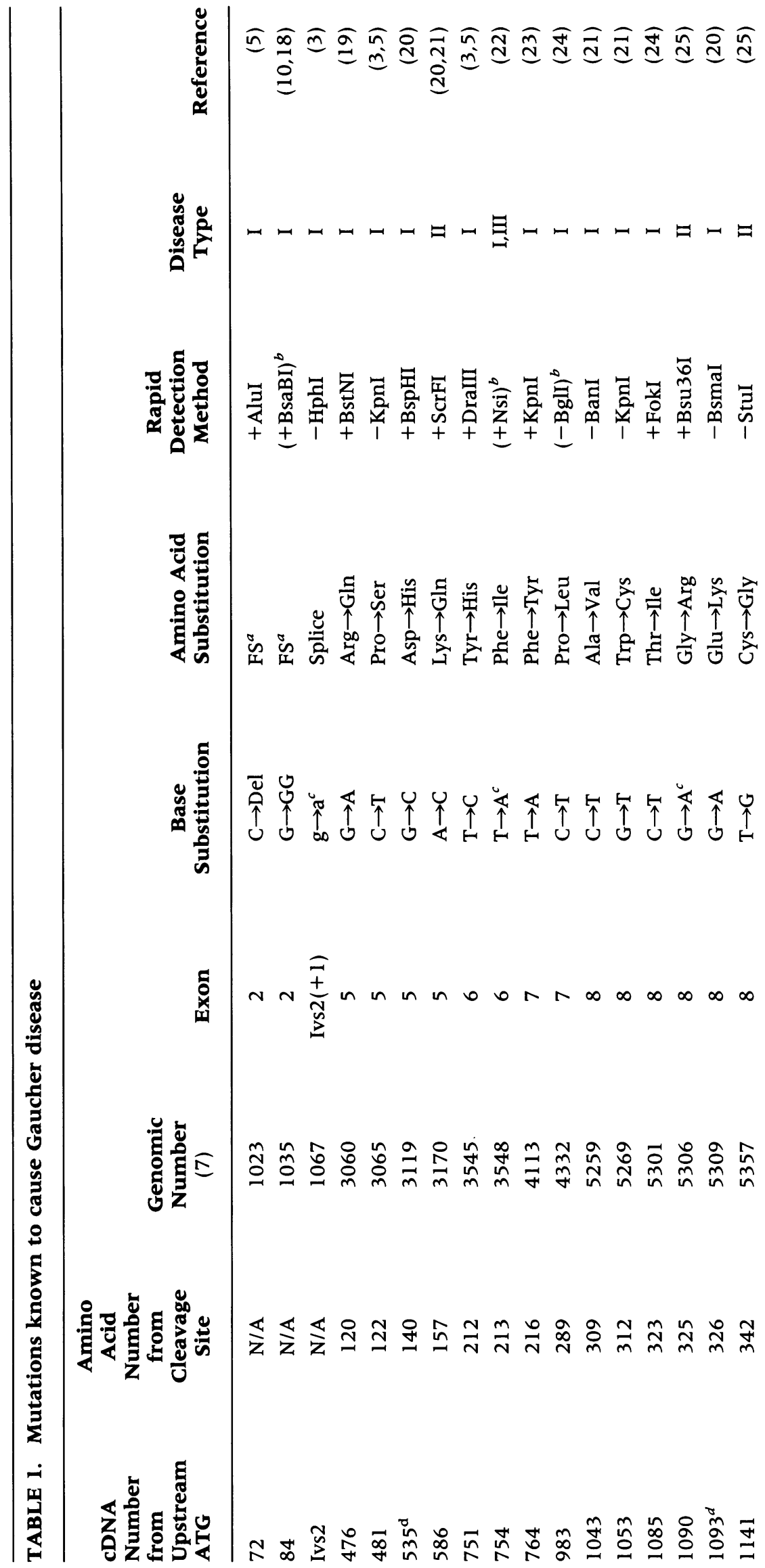




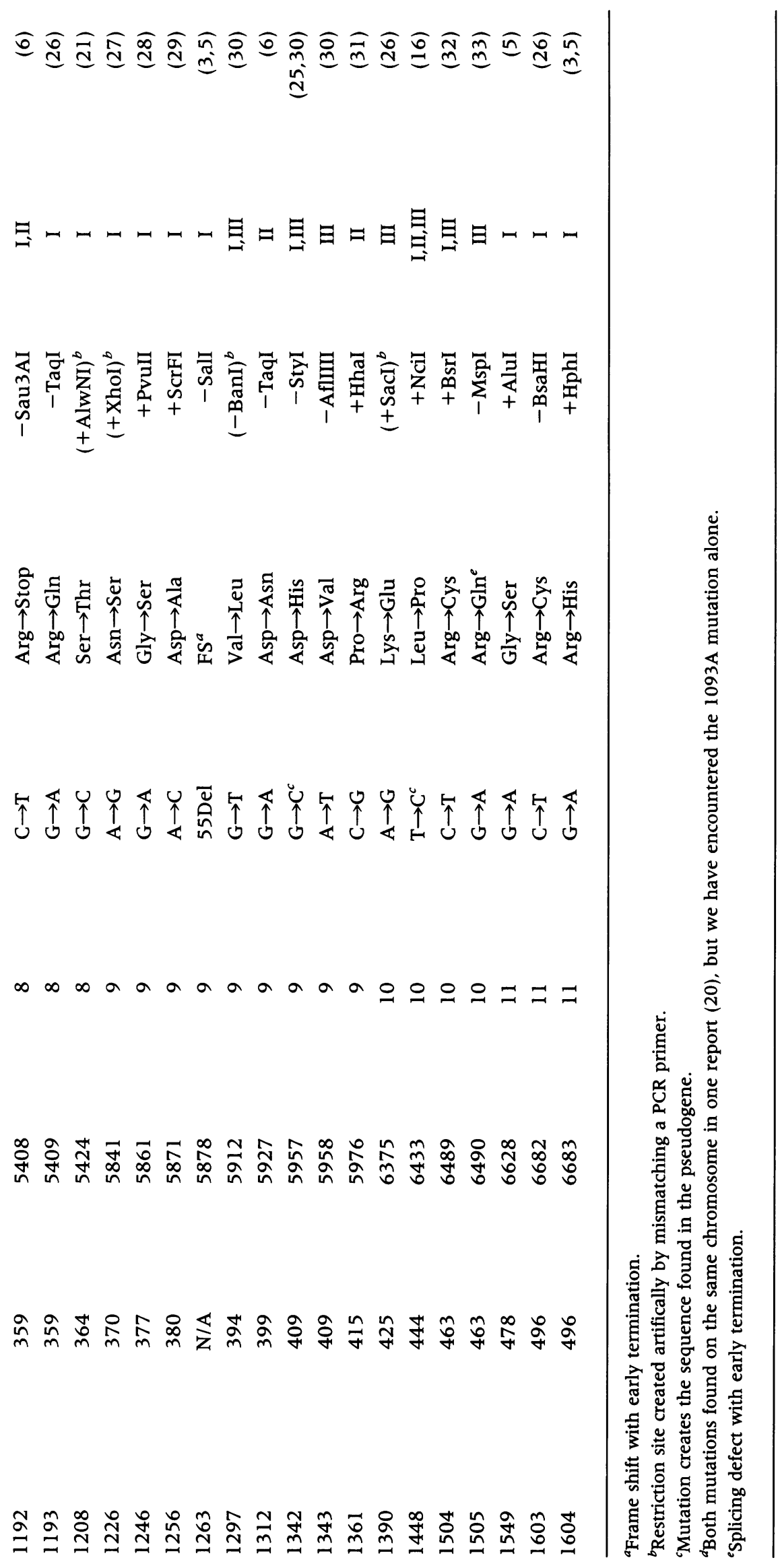


TABLE 2. Number of identified and unidentified Gaucher disease alleles in the subjects of this study

\begin{tabular}{|c|c|c|c|c|c|c|}
\hline & \multicolumn{3}{|c|}{ Jewish } & \multicolumn{3}{|c|}{ Non-Jewish } \\
\hline & Type I & Type II & Type III & Type I & Type II & Type III \\
\hline Total patients & 130 & 0 & 0 & 73 & 7 & 5 \\
\hline $\begin{array}{l}\text { Known mutations } \\
\text { (\# of alleles) }\end{array}$ & 259 & 0 & 0 & 124 & 12 & 9 \\
\hline Unidentified alleles & 1 & 0 & 0 & 22 & 2 & 1 \\
\hline
\end{tabular}

and the $721 \mathrm{~A}$ mutation was found in two additional unrelated patients, one of whom had type II Gaucher disease. Thus, 11 of the 26 mutations were detected.

The mutation in exon 3 was a deletion of a cytosine at nt 203. Instead of the normal six cytosines at this position, only five were found. This patient is a 34-year-old female with moderately severe type I Gaucher disease (severity score $=19$ ) (8). She has recently developed Hodgkin's disease. Her other allele carries the $1226 \mathrm{G}$ mutation (Table 4). The existence of the deletion was confirmed by allele-specific oligonucleotide hybridization (ASOH).

Two patients were found to carry a $\mathrm{C} \rightarrow \mathrm{A}$ transversion in exon 6 at cDNA nt 644 $\left(\mathrm{Ala}^{176} \rightarrow \mathrm{Asp}\right)$. They were unrelated individuals from Germany and Austria, who had been diagnosed at ages 11 and 22 and had mild to moderate disease. This mutation in exon 6 destroys a PflMI site.

The $\mathrm{C} \rightarrow \mathrm{A}$ transversion at cDNA nt 661 $\left({ }^{182}\right.$ Pro $\rightarrow$ Thr $)$ mutation in exon 6 was identified in a 47-year-old male diagnosed at age 12 who now has moderate disease (severity score $=8$ ). This mutation was confirmed by the loss of an HphI restriction site.

The third mutation in exon 6 was a $\mathrm{G} \rightarrow \mathrm{A}$ transition at nt 721 of the cDNA $\left({ }^{202} \mathrm{Gly} \rightarrow \mathrm{Arg}\right)$. This is also the normal sequence of the glucocerebrosidase pseudogene at the corresponding position. The surrounding sequence was not that of the pseudogene and therefore not the product of a crossover or an extensive gene conversion event. An NciI restriction site is destroyed by this mutation. Three patients were found to have this mutation. One of these died at age 3 of type II disease.

The $887 \mathrm{G} \rightarrow$ A mutation $\left({ }^{257} \mathrm{Arg} \rightarrow \mathrm{Gln}\right)$ was found in a 49-year-old non-Jewish Gaucher disease patient with extensive skeletal involvement (severity score $=14$ ). The mutation was confirmed by sequencing the opposite strand and by restriction analysis.

The other mutation found in exon 7, a $\mathrm{C} \rightarrow \mathrm{T}$ transition at cDNA nt $970\left({ }^{285} \mathrm{Arg} \rightarrow\right.$ Cys $)$ was identified in a 39-year-old male of Italian, nonJewish ancestry with moderate disease (severity score $=10$ ). To verify this mutation it was necessary to create an Nsil restriction site by PCR with a mismatched primer (Table 3 ).

In exon 9 a $\mathrm{T} \rightarrow \mathrm{G}$ mutation at nt 1249 $\left({ }^{378} \operatorname{Trp} \rightarrow\right.$ Gly $)$ was found in a patient diagnosed at the age of 20 , now 59 years old, with a severity score of 11 . Since the mutation neither created nor destroyed a restriction site, ASOH was used to confirm this mutation. No other patients were found to have this substitution.

A $1255 \mathrm{G} \rightarrow$ A mutation $\left({ }^{380}\right.$ Asp $\rightarrow$ Asn $)$ was found in exon 9 of a non-Jewish male with type I Gaucher disease. We were able to create an $\mathrm{XcmI}$ restriction site for this mutation by performing PCR with a mismatched primer (Table 3). This patient's other allele has the $1226 \mathrm{G}$ mutation also located in exon 9. This patient also had an abnormal SSCP pattern when exon 10 was examined. Sequencing determined that this was due to a $\mathrm{C} \rightarrow \mathrm{G}$ transversion at $\mathrm{CDNA} \mathrm{nt}$ 1431 , a silent mutation ${ }^{438} \mathrm{Ala} \rightarrow$ Ala. Two daughters did not carry either the $1226 \mathrm{G}$ mutation or the $1431 \mathrm{G}$ silent mutation but both were demonstrated to carry the 1255A mutation. Thus, the $1431 \mathrm{G}$ mutation segregates with the $1226 \mathrm{G} \mathrm{mu}$ tation and appears to represent a second mutational event in this allele. This silent mutation is apparently rare. The DNA from 36 Caucasians, 13 of whom were Hispanic, 12 Ashkenazi Jews, and 12 normal Orientals, representing a total of 116 alleles, were normal at this site as determined by testing an appropriately amplified fragment for cleavage with HinfI. 


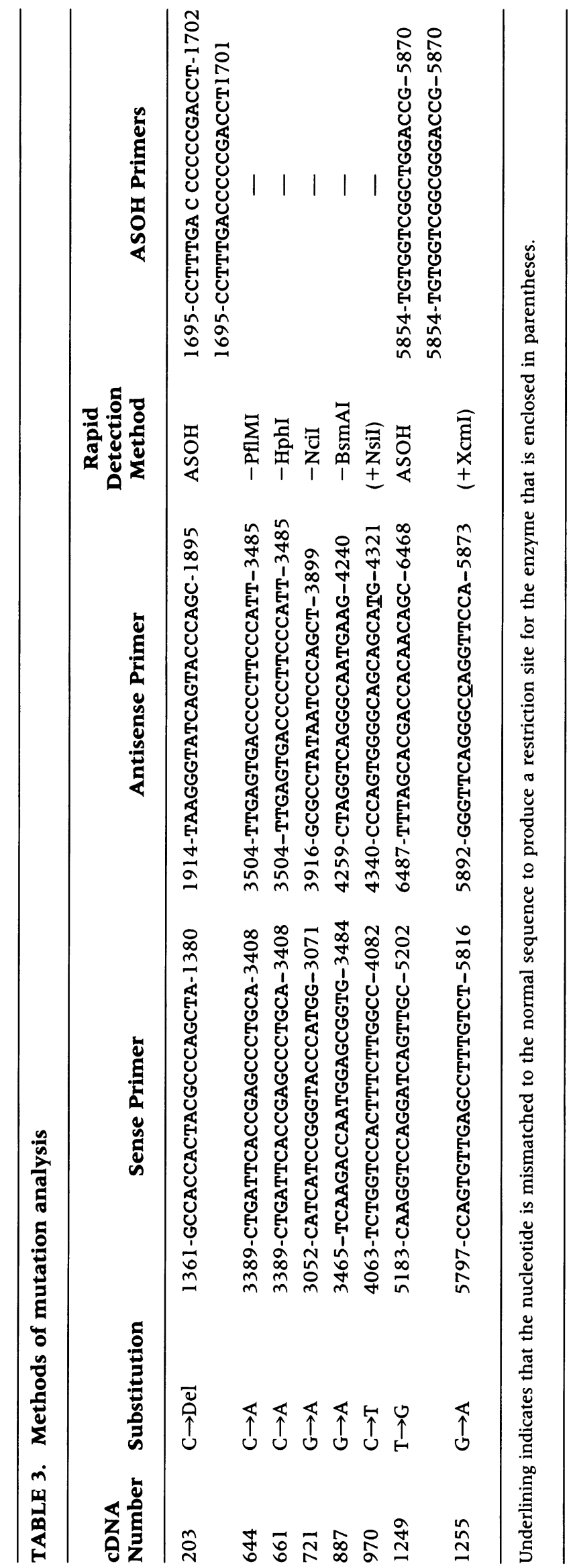




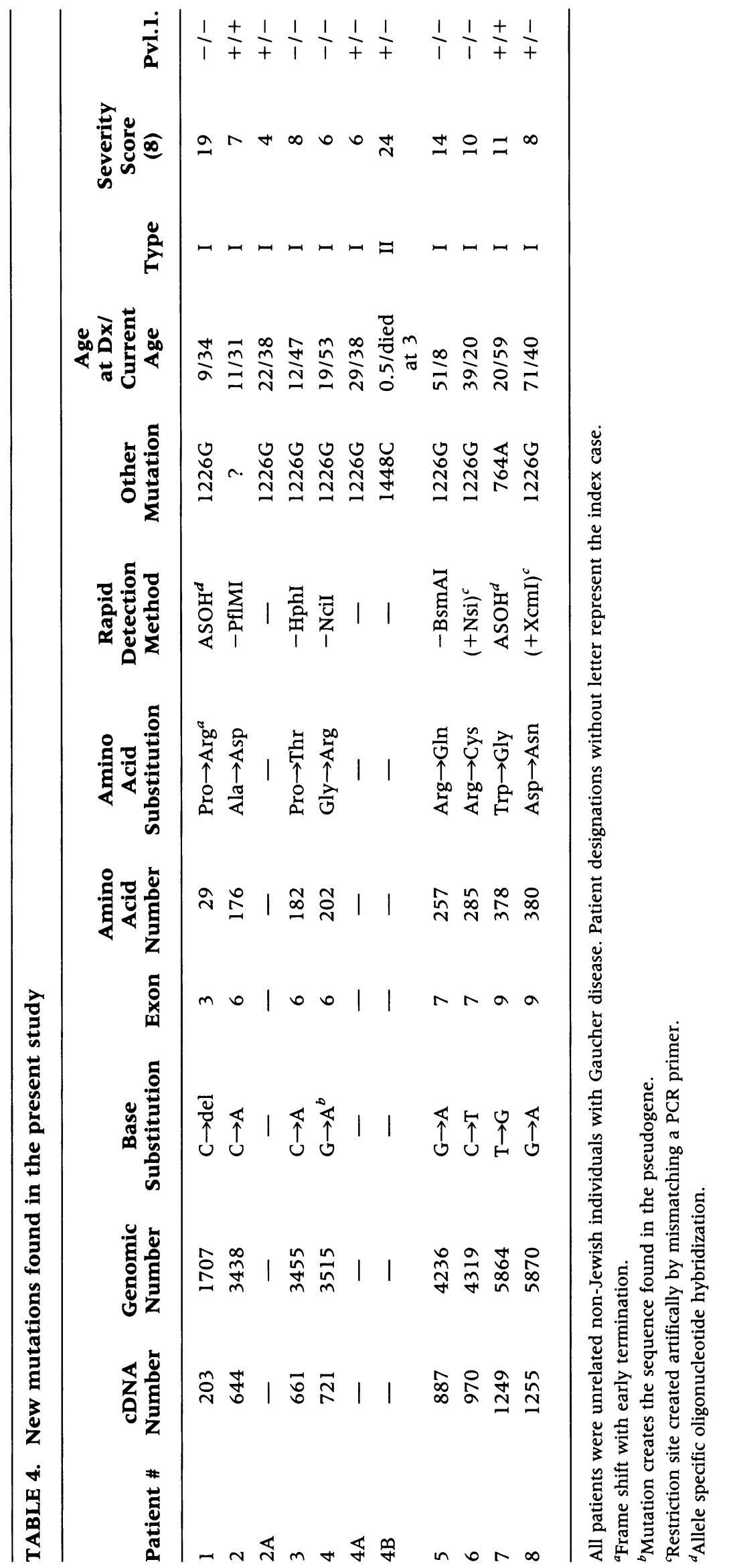


TABLE 5. The expected clinical phenotype when mutations classified as lethal, severe, and mild are combined

\begin{tabular}{|c|c|c|c|c|}
\hline & & \multicolumn{3}{|c|}{ One Allele } \\
\hline & & Lethal & Severe & Mild \\
\hline Other & Lethal & Non-viable & Type II/III & Type I \\
\hline \multirow[t]{2}{*}{ Allele } & Severe & Type II/III & Type II/III & Type I \\
\hline & Mild & Type I & Type I & Type I \\
\hline
\end{tabular}

\section{DISCUSSION}

\section{Severity of Mutations}

Mutations of the glucocerebrosidase gene may be classified on the basis of the severity of the phenotypic effect that they produce. Three types of mutations may be distinguished: lethal, severe, and mild. The expected phenotypic effects of combinations of these types of mutations are summarized in Table 5.

Mutations that prevent the formation of any enzyme at all are considered to be lethal. These include the complete deletion of the gene (9), the 84GG mutation, which causes early termination (10), and the Ivs2 mutation, which prevents splicing of the transcript (3). We regard these as being lethal because they have never been identified either in the homozygous (e.g., 84GG/ $84 \mathrm{GG}$ ) or the combined heterozygous (e.g. $84 G G / \operatorname{Ivs} 2(+1))$ form. The fact that targeted disruption of the murine glucocerebrosidase gene is lethal at or before birth (11) is consistent with this interpretation of such mutations.

Severe mutations include all of those that have been associated with neuronopathic disease, except those that are regarded as being lethal. The prototype of this type of mutation is $1448 \mathrm{C}$, which is often found in the homozygous state, almost invariably with neuropathic disease.

Mild mutations are defined as those that are not associated with neuronopathic disease, even when inherited together with lethal or severe mutations. The $1226 \mathrm{G}$ mutation is the most common of these.

of the new mutations we have found, the deletion at nt 203 may be considered a lethal variant. It produces a frame shift in amino acid 29 with termination at amino acid 51 . The $721 \mathrm{~A}$ mutation can be classified as severe, since it was found in a patient with type II disease. As would be expected, the other mutation in this patient, viz. $1448 \mathrm{C}$, is known to be severe.

In type I patients' classification of mutations by severity is not possible when the new mutation is inherited together with a mild or unidentified mutation; unfortunately, all of the other mutations we have described here are in this category. Both the $1226 \mathrm{G}$ and the $764 \mathrm{~A}$ mutations are known to be mild, and even a severe or lethal mutation inherited with them results in type I disease. The 644A, 661A, 887A, 970T, $1249 \mathrm{G}$, and $1255 \mathrm{~A}$ mutations could all be mild or severe. Only if they were found together with a severe mutation would it be possible to make a definitive classification. If type II or III disease were found in such a patient they would be classified as severe; if such a patient had type I disease, they would be classified as mild.

\section{Population Genetics}

The study of the population genetics of Gaucher disease is facilitated by polymorphic markers that encompass not only the $G B A$ but also the adjacent $P K L R$ gene (12). Although a considerable number of haplotypes exist (13), only two of these are common and are referred to as Pvl.1 $1^{+}$ and Pvl.1- (14). From the point of view of population genetics, the mutations that cause Gaucher disease may be considered to belong to one of two broad classes. There are those that reach polymorphic frequencies in the Jewish population, the $1226 \mathrm{G}, 84 \mathrm{GG}$, Ivs $2(+1)$, mutations and at somewhat lower frequencies, the 1297T, $1604 \mathrm{~A}, 1504 \mathrm{~T}$ mutations. Each of these mutations are always found in the context of a single haplotype (2) and it is a reasonable assumption that each of these mutations only arose once, and that the mutations were amplified in the Jewish population because of some as yet uni- 
dentified selective advantage. Such polymorphic mutations are superimposed upon a background of mutational noise consisting of sporadic mutations that have occurred panethnically. The only one of the panethnic mutations that is relatively common is that at $\mathrm{nt}$ 1448. It is significant that this mutation is found in both common glucerocerebrosidase haplotypes, suggesting that its relatively high prevalence is not due to selection, but rather to a mutational hot spot, in this case based, in all likelihood, on the fact that the same sequence is present in the glucocerebrosidase pseudogene. An exception is the Norbottnian population of Northern Sweden, where the 1448C mutation has reached a very high frequency, presumably as the result of a founder effect (15).

\section{The New Mutations}

In the present study we have identified 8 point mutations, in addition to the 36 that had already been described in the 7 years since the first such mutation was identified (16). The assumption that a cause-and-effect relationship exists between these mutations and the patients' Gaucher disease is a reasonable one, given that in most cases the entire coding region was examined for other mutations and none were found. It is to be expected that mutations found in such a survey will be rare, sporadic mutations and will be found predominantly in the non-Jewish population. This expectation has been largely borne out in the present study. Eight new mutations were found, and only two of these were detected in more than one unrelated person. Thus far there are too few cases of these mutations to be able to determine whether they, like the polymorphic mutations, had a common origin.

In the case of the $721 \mathrm{~A}$ mutation, the other allele in two cases carried the common 1226G mutation. Pvl.l haplotypes were not the same. Haplotype analysis showed that one patient with this mutation was Pvl.1 $/ \mathrm{Pvl} .1^{-}$and the other Pvl.1 $1^{+} / \mathrm{Pv} 1.1^{-}$. This indicates that the new mutation was found in context of both Pvl.1 ${ }^{-}$and Pv1.1 ${ }^{+}$haplotypes, since the other allele carrying the $1226 \mathrm{G}$ is always in the $\mathrm{Pvl}^{-} \mathrm{1}^{-}$context $(2,3,17)$. Thus it is reasonable to conclude that this mutation was the result of two independent mutational events. The mutant sequence matches the normal pseudogene sequence at this location; it could well be a mutational hot spot.
In contrast, the $644 \mathrm{~A}$ mutation was found in context of the Pvl.1 $1^{+}$haplotype in both cases in which it was detected. The first patient had the $\mathrm{Pvl} .1^{+} / \mathrm{Pvl} .1^{+}$genotype; the second patient a Pv1.1 ${ }^{+} / \mathrm{Pv} 1.1^{-}$genotype. The Pvl.1 $1^{-}$allele is always associated with the $1226 \mathrm{G}$ mutation. This establishes that the $644 \mathrm{~A}$ mutation was in the $\mathrm{Pv} 1.1^{+}$context in the second patient. However, the population frequency of the $\mathrm{Pvl} .1^{+}$gene is $30 \%$ in European populations $(12,14)$ and thus there is a $30 \%$ probability that, given a Pvl.1 $1^{+}$ haplotype for the first patient, the second mutation would be in the Pvl.1 $1^{+}$context also.

Fifteen mutant alleles examined by SSCP in this series have not yet been identified. In a few cases there was insufficient DNA available to examine all exons. SSCP is a powerful but not infallible method for the detection of mutations. Complete sequencing of the coding region may reveal mutations missed by SSCP analysis.

\section{ACKNOWLEDGMENT}

This is manuscript 8696-MEM from The Scripps Research Institute. Supported by National Institutes of Health grants DK36639 and RR00833 and the Sam Stein and Rose Stein Charitable Trust Fund.

\section{REFERENCES}

1. Beutler E, Grabowski G. (1994) Gaucher disease. In: Scriver CR, Beaudet AL, Sly WS, Valle D (eds) The Metabolic Basis of Inherited Disease. McGraw-Hill Publishing Company, New York, pp. 2641-2670.

2. Beutler E. (1993) Gaucher disease as a paradigm of current issues regarding single gene mutations of humans. Proc. Natl. Acad. Sci. U.S.A. 90: 5384-5390.

3. Beutler E, Gelbart T, Kuhl W, Zimran A, West C. (1992) Mutations in Jewish patients with Gaucher disease. Blood 79: 1662-1666.

4. Beutler E, Gelbart T. (1993) Gaucher disease mutations in non-Jewish patients. Br. J. Haematol. 85: 401-405.

5. Beutler E, Gelbart T, West C. (1993) Identification of six new Gaucher disease mutations. Genomics 15: 203-205. 
6. Beutler E, Gelbart T. (1994) Two new Gaucher disease mutations. Hum. Genet. 93: 209210.

7. Horowitz M, Wilder S, Horowitz Z, Reiner O, Gelbart T, Beutler E. (1989) The human glucocerebrosidase gene and pseudogene: Structure and evolution. Genomics 4: 87-96.

8. Zimran A, Kay AC, Gelbart T, Garver P, Saven A, Beutler E. (1992) Gaucher disease: Clinical, laboratory, radiologic and genetic features of 53 patients. Medicine 71: 337-353.

9. Beutler E, Gelbart T. (1994) Erroneous assignment of Gaucher disease genotype as a consequence of a complete gene deletion. Hum. Mutat. 4, in press.

10. Beutler E, Gelbart T, Kuhl W, Sorge J, West C. (1991) Identification of the second common Jewish Gaucher disease mutation makes possible population based screening for the heterozygote state. Proc. Natl. Acad. Sci. U.S.A. 88: 10544-10547.

11. Tybulewicz VLJ, Tremblay ML, LaMarca ME, et al. (1992) Animal model of Gaucher's disease from targeted disruption of the mouse glucocerebrosidase gene. Nature 357: 407410.

12. Glenn D, Gelbart T, Beutler E. (1994) Tight linkage of pyruvate kinase $(P K L R)$ and glucocerebrosidase $(G B A)$ genes. Hum. Genet. 93: 635-638.

13. Beutler E, West C, Gelbart T. (1992) Polymorphisms in the human glucocerebrosidase gene. Genomics 12: 795-800.

14. Sorge J, Gelbart T, West C, Westwood B, Beutler E.. (1985) Heterogeneity in type I Gaucher disease demonstrated by restriction mapping of the gene. Proc. Natl. Acad. Sci. U.S.A. 82: 5442-5445.

15. Dahl N, Lagerström M, Erikson A, Pettersson U. (1990) Gaucher disease type III (Norrbottnian type) is caused by a single mutation in exon 10 of the glucocerebrosidase gene. Am. J. Hum. Genet. 47: 275-278.

16. Tsuji S, Choudary PV, Martin BM, et al. (1987) A mutation in the human glucocerebrosidase gene in neuronopathic Gaucher's disease. N. Engl. J. Med. 316: 570-575.

17. Zimran A, Gelbart T, Beutler E. (1990) Linkage of the Pvu II polymorphism with the common Jewish mutation for Gaucher disease. Am. J. Hum. Genet. 46: 902-905.

18. Beutler E. (1991) Gaucher's disease. N. Engl. J. Med. 325: 1354-1360.

19. Graves PN, Grabowski GA, Eisner R, Palese P, Smith FI. (1988) Gaucher disease type 1:
Cloning and characterization of a cDNA encoding acid $\beta$-glucosidase from an Ashkenazi Jewish patient. DNA 7: 521-528.

20. Eyal N, Firon N, Wilder S, Kolodny EH, Horowitz M. (1991) Three unique base pair changes in a family with Gaucher disease. Hum. Genet. 87: 328-332.

21. Latham TE, Theophilus BDM, Grabowski GA, Smith FI. (1991) Heterogeneity of mutations in the acid $\beta$-glucosidase gene of Gaucher disease patients. DNA Cell Biol. 10: 15-21.

22. Kawame H, Eto Y. (1991) A new glucocerebrosidase-gene missense mutation responsible for neuronopathic Gaucher disease in Japanese patients. Am. J. Hum. Genet. 49: 1378-1380.

23. Beutler E, Gelbart T. (1990) Gaucher disease associated with a unique KpnI restriction site: Identification of the amino acid substitution. Ann. Hum. Genet. 54: 149-153.

24. He G-S, Grace ME, Grabowski GA. (1992) Gaucher disease: Four rare missense mutations encoding F213I, F289Y, T323I, and R463C in type I variants. Hum. Mutat. 1: 423-427.

25. Eyal N, Wilder S, Horowitz M. (1990) Prevalent and rare mutations among Gaucher patients. Gene 96: 277-283.

26. Kawame H, Hasegawa Y, Eto Y, Maekawa K. (1992) Rapid identification of mutations in the glucocerebrosidase gene of Gaucher disease patients by analysis of single-strand conformation polymorphisms. Hum. Genet. 90: 294-296.

27. Tsuji S, Martin BM, Barranger JA, Stubblefield BK, LaMarca ME, Ginns EI. (1988) Genetic heterogeneity in type 1 Gaucher disease: Multiple genotypes in Ashkenazic and non-Ashkenazic individuals. Proc. Natl. Acad. Sci. U.S.A. 85: 2349-2352, 5708.

28. Laubscher $\mathrm{KH}$, Glew RH, Lee RE, Okinaka RT. (1994) Use of denaturing gradient gel electrophoresis to identify mutant sequences in the $\beta$-glucosidase gene. Hum. Mutat. 3: 411-415.

29. Walley AJ, Harris A. (1993) A novel point mutation (D380A) and a rare deletion (1255del55) in the glucocerebrosidase gene causing Gaucher's disease. Hum. Mol. Genet. 2: 1737-1738.

30. Theophilus BDM, Latham T, Grabowski GA, Smith FI (1989) Comparison of RNase A, chemical cleavage, and GC-clamped dena- 
turing gradient gel electrophoresis for the detection of mutations in exon 9 of the human acid -glucosidase gene. Nucl. Acids Res. 17: 7707-7722.

31. Wigderson $M$, Firon N, Horowitz Z, et al. (1989) Characterization of mutations in Gaucher patients by cDNA cloning. Am. J. Hum. Genet. 44: 365-377.
32. Hong CM, Ohashi $\mathrm{T}$, Yu XJ, Weiler S, Barranger JA. (1990) Sequence of two alleles responsible for Gaucher disease. DNA. Cell. Biol. 9: 233-241.

33. Ohshima T, Sasaki M, Matsuzaka T, Sakuragawa N. (1993) A novel splicing abnormality in a Japanese patient with Gaucher's disease. Hum. Mol. Genet. 2: 1497-1498. 